\title{
Validitas Media Pembelajaran Statistika Berbasis Android dengan Teknik Peta Konsep untuk Meningkatkan Pemahaman Konsep Statistika
}

\author{
Syelfia Dewimarni ${ }^{1}$, Rizalina $^{2}$, Zefriyenni $^{3}$ \\ ${ }^{1,2}$ Prodi Sistem Informasi, Fakultas Ilmu Komputer, Universitas Putra Indonesia YPTK Padang \\ ${ }^{3}$ Prodi Magister Manajemen, Program Pasca Sarjana, Universitas Putra Indonesia YPTK Padang \\ J1. Raya Lubuk Begalung, Padang-Sumatera Barat. \\ Syelfia.dewimarni@gmail.com
}

\begin{abstract}
The purpose of this research is to produce Android-Based Statistikal Learning Media products with Concept Map Techniques to Improve Understanding of Statistikal Concepts of Students of Information Systems Study Program of Putra Indonesia University YPTK Padang. The type of this research is Research and Development (R\&D). The development model used is the Plomp development model. In this research, the development stage was carried out, called the creation of protoype (prototype phase) validation of Android-Based Statistikal Learning Media products with Concept Map Techniques. The product is validated by three experts, linguists, mathematicians, and educational technology experts. The aspects seen are Presentation / Didactic, Content Feasibility, Language and Radiography / Display. The instrument used is a validation sheet in the form of a questionnaire using the likert scale. Obtained validation results for Android-Based Statistikal Learning Media products with Concept Map Techniques to improve the concept understanding ability of students on Putra Indonesia University YPTK Padangin information systems study program is 3.75 with a very valid category.
\end{abstract}

Keywords: Learning Media, Android, Statistiks, Concept Understanding

\begin{abstract}
Abstrak
Tujuan penelitian ini adalah menghasilkan produk Media Pembelajaran Statistika Berbasis Android Dengan Teknik Peta Konsep Untuk Meningkatkan Pemahaman Konsep Statistika Mahasiswa Program Studi Sistem Informasi Universitas Putra Indonesia YPTK Padang. Jenis penelitian ini adalah penelitian pengembangan (Research and Development, R\&D). Model pengembangan yang digunakan adalah model pengembangan Plomp. Pada penelitian ini dilakukan tahapan pengembangan yaitu pembuatan prototype (protoype phase) validasi produk Media Pembelajaran Statistika Berbasis Android Dengan Teknik Peta Konsep. Produk divalidasi oleh tiga ahli yaitu ahli Bahasa, ahli matematika dan ahli teknologi Pendidikan. Adapun aspek yang dilihat adalah Penyajian/ Didaktik, Kelayakan Isi, Bahasa dan Kegrafikan/Tampilan. Instrument yang digunakan adalah lembar validasi berupa angket dengan menggunakan skala likert. Diperoleh hasil validasi untuk produk Media Pembelajaran Statistika Berbasis Android Dengan Teknik Peta Konsep untuk meningkatkan kemampuan pemahaman konsep mahasiswa program studi sistem informasi universitas putra Indonesia YPTK Padang adalah sebesar 3,75 dengan kategori sangat valid.
\end{abstract}

Kata kunci: Media Pembelajaran, Android, Statistika, Pemahaman Konsep

Copyright (c) 2022 Syelfia Dewimarni, Rizalina, Zefri Yenni

$\triangle$ Corresponding author: Syelfia Dewimarni

Email Address: Syelfia.dewimarni@gmail.com (Jl. Raya Lubuk Begalung, Padang-Sumatera Barat)

Received 25 October 2021, Accepted 06 January 2022, Published 16 Januari 2022

\section{PENDAHULUAN}

Pembelajaran tatap muka selama ini beralih ke pembelajaran jarak jauh atau daring. Hal ini tidak lain adalah dampak dari covid 19 yang bersifat pandemi yang juga dirasakan oleh Indonesia. Dalam hal pembelajaran agar supaya tujuan pembelajaran dapat tercapai dengan baik meskipun telah bertukar metode dari pembelajaran langsung ke pembelajaran daring, hal ini tidak boleh membuat tujuan pembelajaran terabaikan. Kompetensi pedagogik mensyaratkan pengajar untuk dapat merancang media pembelajaran, mengembangkan pembelajaran dan memanfaatkan teknologi pembelajaran (Rudi Setiawan, 2020). Salah satu usaha untuk mewujudkan tercapainya tujuan pembelajaran itu dengan baik adalah dibutuhkannya kreatifitas seorang pengajar atau dosen dalam 
memilih media penghubung dengan mahasiswanya agar dapat terjadi komunikasi yang baik. Menurut (syaful \& Arswan, 2010) mengungkapkan media pembelajaran adalah alat bantu apa saja yang dapat dijadikan sebagai penyalur pesan agar tercapai tujuan pembelajaran. hal ini sejalan dengan yang di ungkapkan oleh (Hamzah, 2011) "Media pembelajaran adalah segala bentuk alat komunikasi yang dapat digunakan untuk menyampaikan informasi dari sumber ke peserta didik secara terencana sehingga tercipta lingkungan belajar yang kondusif dimana penerimanya dapat melakukan proses belajar secara efisien dan efektif “. Lebih jelasnya Gerlach \& Ely (2013) mengungkapkan "media pembelajaran memiliki cakupan yang sangat luas, yaitu termasuk manusia, materi atau kajian yang membangun suatu kondisi yang membuat peserta didik mampu memperoleh pengetahuan, keterampilan atau sikap. Media pembelajaran mencakup semua sumber yang diperlukan untuk melakukan komunikasi dalam pembelajaran, sehingga bentuknya bisa berupa perangkat keras (hardware), seperti komputer, TV, projector, dan perangkat lunak (software) yang digunakan pada perangkat keras itu.".

Media pembelajaran berbasis android ini mudah diaplikasikan pada mahasiswa karena pada umumnya setiap mahasiswa sudah memiliki smartphone atau android. Mata kuliah statistika diajarkan pada semester ke 2 pada tahun pertama, hal ini berarti rentang umur mahasiswa adalah berkisar 18-20 tahun yang mana rentang umur pada kisaran ini dilabeli dengan generasi Z. pemilihan media pembelajaran berbasis android ini selain dengan pemaparan dari (Https://Lpmpjatim.Kemdikbud.Go.Id/Site/Detailpost/Gen-z-Pendidikan-Harus-Bertransformasi, n.d.) bahwa Generasi Z ini dilabeli juga sebagai generasi yang minim batasan (boundary-less generation). Secara usia, Gen $\mathrm{Z}$ saat ini berkisaran antara usia 8-23 tahun yaitu usia "produktif" dibangku sekolah/perguruan tinggi. Dengan karakteristik tersebut tentu pemangku kebijakan pendidikan harus mampu meramu dan menyiapkan suatu konsep pendidikan yang tepat bagi Gen Z. Pendidikan harus mampu bertransformasi menjadi pendidikan era Gen Z, tidak lagi pendidikan yang klasik (guru berbicara di depan kelas, siswa mendengarkan sambil mengantuk).

Menurut Almas Dkk bahwa penerapan pembelajaran dengan media pembelajaran berbasis Android mendapatkan respon yang sangat efektif. Sejalan dengan itu Insar, Bayu (2019) mengatakan Mobile learning has also influenced the teaching and learning process and students' achievement Future studies can also focus on research and development of mobile learning and its application in a more diverse field of science" bahwa pembelajaran dengan seluler telah mempengaruhi pengajaran dan proses belajar serta prestasi siswa. Penelitian akan hal ini dapat menjadi fokus untuk pengembangan pembelajaran dan dapat digunakan pada pembelajaran yang beragam.

Menurut (Dajan, 1995) Statistika adalah ilmu mengumpulkan, menata, menyajikan, menganalisis, dan menginterpretasikan data menjadi informasi untuk membantu pengambilan keputusan yang efektif. Istilah statistika dapat pula diartikan sebagai metode untuk mengumpulkan, mengolah, menyajikan, menganalisis, dan menginterpretasikan data dalam bentuk angka-angka. Di 
Validitas Media Pembelajaran Statistika Berbasis Android dengan Teknik Peta Konsep untuk Meningkatkan Pemahaman Konsep Statistika, Syelfia Dewimarni, Rizalina, Zefriyenni

bidang komputasi, statistika dapat pula diterapkan dalam pengenalan pola maupun kecerdasan buatan (Vulandari, 2018).

Statistika merupakan mata kuliah wajib di jurusan Sistem Informasi Universitas Putra Indonesia YPTK Padang. Mata kuliah statistika diambil pada semester genap tahun pertama. Adapaun topik-topik yang ada pada mata kuliah statistika antara lain: Konsep statistika dan Notasi Penjumlahan, distribusi frekuensi, ukuran statistik, probabilitas, distribusi teoritis, pengujian hipotesa, uji chi kuadrat, regresi dan korelasi, aplikasi program statistik komputer (SPSS/Excell). Tujuan mata kuliah ini adalah agar mahasiswa mampu menerapkan konsep-konsep dari topik di atas dalam penyelesaian masalah yang berhubungan dengan statistika dengan benar dan tepat. Untuk itu materi statistika ini di dampingi oleh Teknik peta konsep guna mendukung ketercapaian tujuan pembelajaran statistika. Kemampuan pemahaman konsep adalah termasuk kepada kemampuan matematis (NCTM, 1989) dan Penerapan konsep dengan benar merupakan salah satu indikator kemampuan pemahaman konsep (Dewimarni,S. 2017) Peta konsep memiliki pengaruh yang signifikan terhadap hasil pembelajaran matematika, seperti yang diungkpakan oleh (Shinta. K.W., 2017).

Kemampuan pemahaman konsep mahasiswa program studi sistem informasi pada mata kuliah statistika ini masih jauh dari yang diharapkan. Hal ini dapat dilihat dari hasil ujian tengah semester ganjil 2020 dimana 30\% mahasiswa memperoleh nilai (C) Cukup. Diharapkan dengan dilatihnya kemampuan pemahaman konsep mahasiswa dengan tujuan dapat meningkatkan pemahaman konsep dan hasil belajar pada mata kuliah Statistika.

Media pembelajaran yang baik adalah media pembelajaran yang valid, praktis dan efektif. Hal ini sejalan dengan yang dinyatakan oleh Rina dalam (Annisa. D. F Dkk, 2017) suatu media pembelajaran yang telah dikembangkan dapat dikatakan berkualitas jika memenuhi 3 standar kriteria penilaian yaitu kriteria valid, praktis, dan efektif. Validitas yaitu suatu ukuran yang menunjukkan tingkat kesahihan suatu produk yang telah dikembangkan dengan mengacu pada beberapa aspek penilaian. Ada 2 aspek yang menjadi syarat sehingga media dikatakan kevalidan yaitu: (1) Validasi isi yaitu jika produk dikatakan dikembangkan memiliki dasar teori yang memadai; (2) Validasi konstruk yaitu jika semua komponen produk antara satu dengan yang lainnya berhubungan secara konsisten (Hafiz, 2013) Proses validasi produk dilakukan oleh validator dalam hal ini dosen atau para ahli yang telah berpengalaman menilai suatu produk baru. Hasil analisis tersebut dijadikan sebagai pedoman untuk merevisi/memperbaiki kekurangan produk setelah melalui proses validasi (Jusniar \& Sumiati, 2014). Berdasarkan paparan di atas peneliti melakukan penelitian dengan judul "Validitas Media Pembelajaran Statistika Berbasis Android dengan Teknik Peta Konsep untuk Meningkatkan Pemahaman Konsep Statistika”.

\section{METODE}

Jenis penelitian ini adalah penelitian pengembangan atau Research and Development ( $\& \& D)$. 
Tujuan penelitian ini adalah menghasilkan produk berupa media pembelajaran statistika berbasis android dilengkapi dengan Teknik peta konsep untuk meningkatkan kemampuan pemahaman konsep statistika mahasiswa program studi Sistem Informasi Universitas Putra Indonesia YPTK Padang. Model pengembangan yang digunakan yaitu Model Plomp (Plomp, 2013), Model Plomp mempunyai tiga tahapan yaitu Tahap investigasi awal (preliminary research), Tahap pembuatan prototipe (prototyping phase) dan Tahap evaluasi (assessment phase).

Pada tahap investigasi awal (preliminary research), pada Analisa kebutuhan peneliti dapat menyimpulkan bahwa dibutuhkan media pembelajaran statistika berbasis android ini sebagai media pembelajaran dimasa Covid 19 yang melakukan pembelajaran jarak jauh atau daring (Dewimarni, S. 2021). Setelah hasil investigasi awal peneliti melanjutkan ke tahap pembuatan prototipe (prototyping phase) dengan menghasilkan produk awal pengembangan dilakukan pada media pembelajaran statistika berbasis android yang sesuai dengan Analisa kebutuhan.

Pada tahapan pembuatan prototipe (prototyping phase) memvalidasi produk. Produk di validasi oleh 3 orang ahli, yang terdiri ahli Bahasa Indonesia, ahli matematika dan ahli teknologi pendidikan.

Alat pengumpul data adalah lembar validasi berupa angket. Analisis angket dilakukan dengan menggunakan skala likert, yang langkah-langkahnya sebagai berikut:

a. Lembar validasi yang telah dinilai, disajikan dalam bentuk tabel dengan cara memberikan skor setiap jawaban seperti pada Tabel 1 .

Tabel 1. Cara Memberi Skor Pada Analisis Data Validitas

\begin{tabular}{|cc|}
\hline Alternatif Jawaban & Skor \\
\hline Sangat Valid & 4 \\
\hline Valid & 3 \\
\hline Cukup Valid & 2 \\
\hline Kurang Valid & 1 \\
\hline Tidak Valid & 0 \\
\hline
\end{tabular}

b. Menentukan jumlah skor dan rata-rata yang diberikan validator untuk setiap item, dengan menggunakan rumus:

$$
\overline{x_{l}}=\frac{\sum_{i=1}^{n} x_{i}}{n}
$$

Keterangan:

$\overline{x_{l}}=$ rata-rata tiap item

$x_{i}=$ skor yang diiberikan validator $i$

$n=$ jumlah validator

(Walpole, 1992:23)

c. Menentukan validitas perangkat pembelajaran dengan menggunakan rumus: 
Validitas Media Pembelajaran Statistika Berbasis Android dengan Teknik Peta Konsep untuk Meningkatkan Pemahaman Konsep Statistika, Syelfia Dewimarni, Rizalina, Zefriyenni

$$
R=\frac{\sum_{j=1}^{m} \overline{x_{j}}}{m}
$$

Keterangan:

$R=$ validitas perangkat pembelajaran

$\overline{x_{J}}=$ rerata hasil penilaian item $\mathrm{ke}-\mathrm{j}$

$m=$ banyak item

Kriteria untuk mendapatkan tingkat kevalidan perangkat pembelajaran menggunakan kriteria seperti pada Tabel 2.

Tabel 2. Kriteria Validitas Perangkat Pembelajaran

\begin{tabular}{|cc|}
\hline Rata-rata & Kriteria \\
\hline $\mathrm{R}>3,20$ & Sangat Valid \\
\hline $2,40<\mathrm{R} \leq 3,20$ & Valid \\
\hline $1,60<\mathrm{R} \leq 2,40$ & Cukup Valid \\
\hline $0,80<\mathrm{R} \leq 1,60$ & Kurang Valid \\
\hline $\mathrm{R} \leq 0,80$ & Tidak Valid \\
\hline
\end{tabular}

Sumber: (Muliyardi, 2006)

Alat pengumpul data atau instrument validasi adalah berupa angket lembar validasi untuk masing-masing ahli. Angket menggunakan skala likert. Ahli bahasa menilai tentang perihal Bahasa seperti jenis tulisan mudah di baca dan menarik. Cara penulisan symbol, persamaan matematika, apakah bahasa pada media sudah sesuai dengan tingkat pemahaman dan pengalaman mahasiswa. Sementara itu aspek kegrafikan dinilai oleh ahli Teknologi Pendidikan. Yang termasuk kedalam kegrafikan ini adalah Tata letak isi Media Pembelajaran Statistika Berbasis Android menarik, Gambar yang disajikan dalam Media Pembelajaran Statistika Berbasis Android berupa konteks mata kuliah statistika, Letak gambar dan kalimat huruf pada Media Pembelajaran Statistika Berbasis Android sesuai dan strategis, Desain tampilan Media Pembelajaran Statistika Berbasis Android menunjukkan ciri khas mata kuliah statistika, Memudahkan mahasiswa untuk memahami masalah peta konsep, serta judul dan bagian yang membutuhkan penekanan dicetak tebal dengan warna apakah sudah menarik.

\section{HASIL DAN DISKUSI}

Pada penelitian ini dilakukan tahap validasi produk berupa Media Pembelajaran Statistika Berbasis Android Dengan Teknik Peta Konsep. Penelitian ini dilakukan pada Program Studi Sistem Informasi Universitas Putra Indonesia YPTK Padang. Kegiatan validasi pada Media Pembelajaran Statistika Berbasis Android Dengan Teknik Peta Konsep divalidasi oleh 3 pakar/ahli yakni dosen dosen ahli bidang bahasa, ahli bidang matematika, dan dosen ahli teknologi pendidikan.

Validasi aspek kelayakan isi dinilai oleh ahli matematika, Adapun aspek dari penyajian dan kelayakan isi adalah yang pertama aspek penyajian (1) Pengorganisasian materi dalam Media Pembelajaran Statistika Berbasis Android tersusun secara sistematis (2) Media Pembelajaran 
Statistika Berbasis Android menyajikan materi secara sistematis (3) Media Pembelajaran Statistika Berbasis Android menyajikan Peta Konsep pada setiap materi dengan jelas (4) Media Pembelajaran Statistika Berbasis Android menuntun mahasiswa untuk mengkontruksikan konsep pengetahuannya sendiri (5) Media Pembelajaran Statistika Berbasis Android menuntut peserta didik unutk berinteraktif dalam proses pembelajaran (6) Media Pembelajaran Statistika Berbasis Android memberi kesempatan pada peserta didik untuk dapat belajar aktif (7) Penggunaan Media Pembelajaran Statistika Berbasis Android meningkatkan dan memudahkan Dosen sebagai fasilitator dalam perkuliahan Statistika. Aspek kedua yaitu kelayakan isi, mempunyai indikator penilaian sebagai berikut: (1) Materi pada Media Pembelajaran Statistika Berbasis Android mengacu pada Rencana Pembelajaran Semester (2) Keterkaitan antar materi pembelajaran terkonsep dengan jelas (3) Media Pembelajaran Statistika Berbasis Android sesuai dengan karakteristik dan kebutuhan mahasiswa jurusan Sistem Informasi (4) Kebenaran substansi materi pada Media Pembelajaran Statistika Berbasis Android dapat dipertanggungjawabkan dan (5) Media Pembelajaran Statistika Berbasis Android membantu mahasiswa dalam perkuliahan Statistika.

Hasil validasi Media Pembelajaran Berbasis Android Dengan Teknik Peta Konsep Untuk Meningkatkan Pemahaman Konsep Statistika Program Studi Sistem Informasi Universitas Putra Indonesia YPTK Padang dapat dilihat pada Tabel 3.

Tabel 3. Hasil Validasi Media Pembelajaran Berbasis Android Dengan Teknik Peta Konsep Untuk Meningkatkan Pemahaman Konsep Statistika oleh Para Ahli

\begin{tabular}{|c|l|c|c|}
\hline No & \multicolumn{1}{|c|}{ Aspek yang Dinilai } & Rata-rata & Kategori \\
\hline 1 & Penyajian/ Didaktik & $\mathbf{3 . 7 5}$ & Sangat Valid (SV) \\
\hline 2 & Kelayakan Isi & $\mathbf{3 . 6 0}$ & Sangat Valid (SV) \\
\hline 3 & Bahasa & $\mathbf{4 . 0 0}$ & Sangat Valid (SV) \\
\hline 4 & Kegrafikan/Tampilan & $\mathbf{3 . 7 1}$ & Sangat Valid (SV) \\
\hline \multicolumn{2}{|c|}{ Rata-rata Total } & $\mathbf{3 , 7 5}$ & Sangat Valid (SV) \\
\hline
\end{tabular}

Sumber: Analisis Hasil Validasi media pembelajaran statistika berbasis android oleh Para Ahli

Berdasarkan Tabel 3. diperoleh rata-rata hasil validasi Media Pembelajaran Statistika Berbasis Android Dengan Teknik Peta Konsep Untuk Meningkatkan Pemahaman Konsep Statistika Program Studi Sistem Informasi Universitas Putra Indonesia YPTK Padang adalah 3,75 dengan kategori sangat valid dengan sedikit saran perbaikan.

Adapun saran atau komentar dari para validator adalah validator ahli Bahasa yaitu Bapak Jendri Mulyadi, S.S., M.Hum menyarankan bahwa perbaiki ejaaan beberapa istilah/ kosa kata karena masih ada yang menggunakan ejaan asing (Bahasa inggris). Validator selanjutnya adalah ahli dari bidang teknologi Pendidikan yaitu Ibu Monica Fransisca, S.Pd, M.Pd.T dengan memberikan komentar bahwa media android sudah sangat baik dan menarik, perlu ditambahkan Tambahkan petunjuk penggunaan / navigasi dari aplikasi sehingga dapat digunakan pada mata kuliah statistika. Dan validator yang 
Validitas Media Pembelajaran Statistika Berbasis Android dengan Teknik Peta Konsep untuk Meningkatkan Pemahaman Konsep Statistika, Syelfia Dewimarni, Rizalina, Zefriyenni

terakhir yaitu ahli bidang matematika Ibu Mishbah Ulhusna, S.Si, M.Si memberikan komentar bahwa penyajian materi melalui media pembelajaran berbasis android sudah sesuai dengan RPS Statistika, sedikit diperhatikan pada penggunaan Bahasa dalam latihan kalimat perintah soal lebih jelas lagi agar mudah dipahami. Diharapkan dengan adanya media pembelajaran berbasis android ini meningkatkan pemahaman statistika mahasiswa. Beberapa saran dan hasil perbaikan dari pada validator, dapat dilihat pada Tabel 4 berikut.

Tabel 4. Saran Validator dan Revisi Media Pembelajaran Statistika Berbasis Android

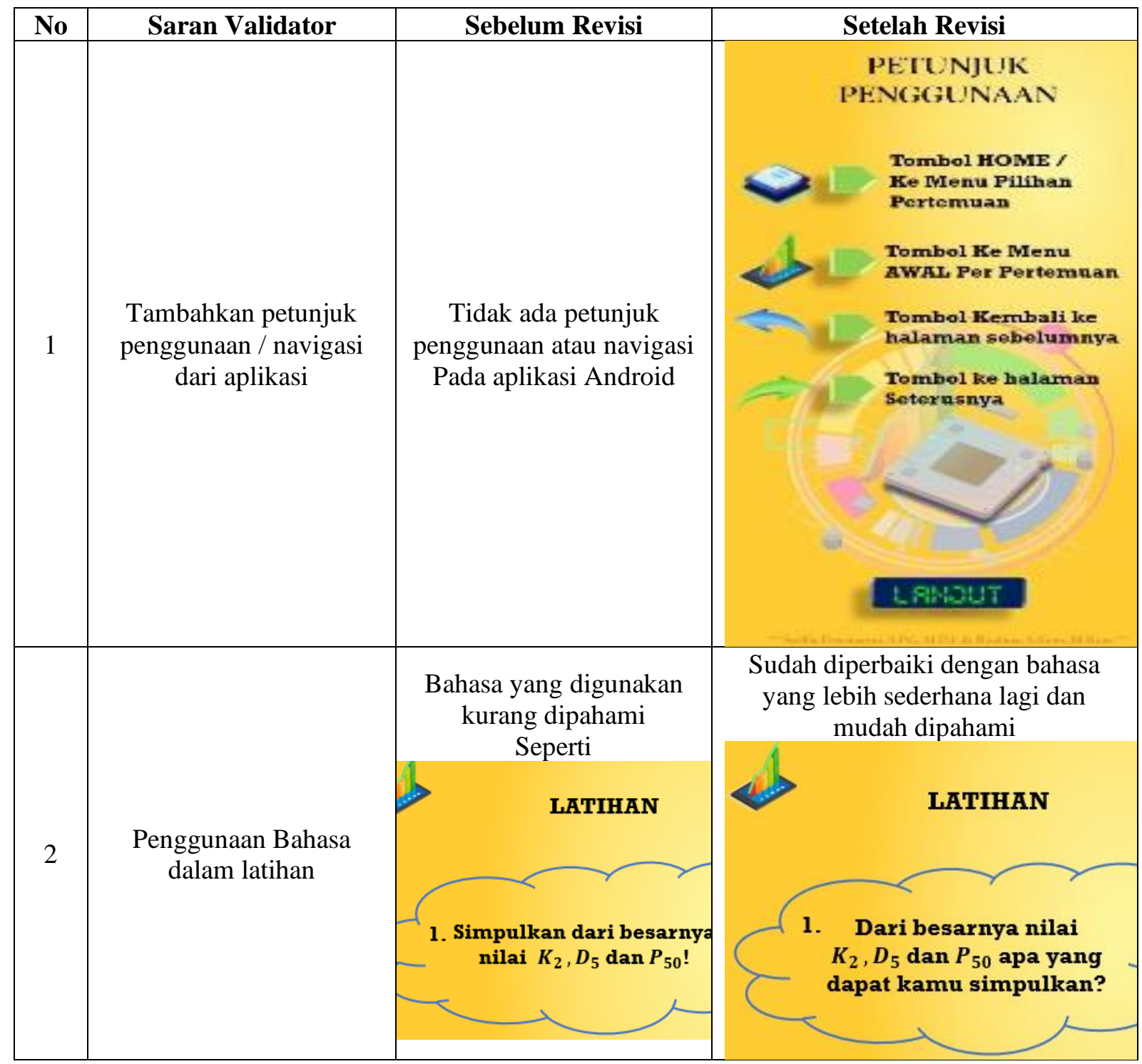




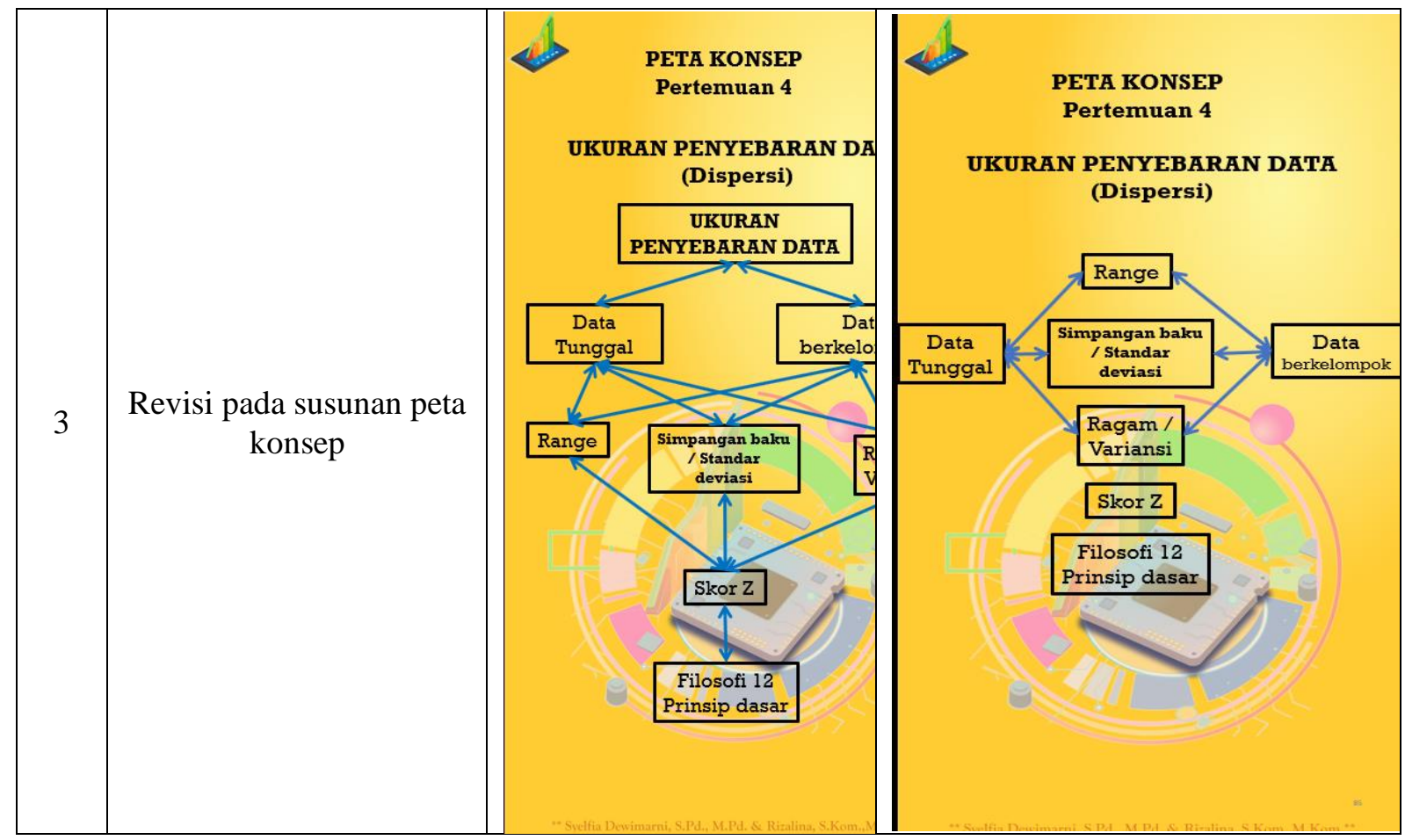

Berdasarkan validator uji ahli teknologi pendidikan, ahli bahasa dan ahli menyatakan bahwa prototype I telah dinyatakan valid dan layak diujicobakan dengan revisi sesuai saran.

\section{KESIMPULAN}

Berdasarkan hasil dari analisis data lembar validasi yang telah diisi oleh para ahli, yaitu antara lain ahli Bahasa, ahli matematika, dan ahli teknologi Pendidikan diperoleh hasil validasi Media Pembelajaran Statistika Berbasis Android Dengan Teknik Peta Konsep Untuk Meningkatkan Pemahaman Konsep Statistika Program Studi Sistem Informasi Universitas Putra Indonesia YPTK Padang adalah sebesar 3,75 dengan kategori sangat valid. Hal ini dapat diartikan bahwa Media Pembelajaran Berbasis Android Dengan Teknik Peta Konsep Untuk Meningkatkan Pemahaman Konsep Statistika Program Studi Sistem Informasi Universitas Putra Indonesia YPTK Padang sudah dapat dilakukan tahapan penelitian selanjutnya yaitu tahapan untuk melihat kepraktisan dan keefektifan dari Media Pembelajaran Berbasis Android Dengan Teknik Peta Konsep Untuk Meningkatkan Pemahaman Konsep Statistika Program Studi Sistem Informasi Universitas Putra Indonesia YPTK Padang.

\section{UCAPAN TERIMA KASIH}

Dalam penelitian ini penulis mengucapkan terima kasih kepada Yayasan Perguruan Tinggi komputer YPTK Padang terkhusus kepada ibu Dr. Hj. Zerni Melmusi, MM. Ak. CA._dan Bapak H. Herman Nawas (alm) Alfatihah untuk Ayahanda UPI YPTK Padang. Dimana, Berkat dukungan Hibah dari Yayasan tahun 2021 sehingga penelitian dapat dilaksanakan. 
Validitas Media Pembelajaran Statistika Berbasis Android dengan Teknik Peta Konsep untuk Meningkatkan

Pemahaman Konsep Statistika, Syelfia Dewimarni, Rizalina, Zefriyenni

\section{REFERENSI}

Annisa. D. F Dkk. (2017). Development Of Picture Media Based On Local Potency For Learning Materials Biodiversity In Class X SMA 1 Pitu Riase Kab. Sidrap. Auladuna: Jurnal Pendidikan Dasar Islam, Vol. 4 No.

Dajan, A. (1995). Pengantar Metode Statistik Jilid I. LP3S.

Dewimarni, S. (2017). Kemampuan Komunikasi Dan Pemahaman Konsep Aljabar Linier Mahasiswa Universitas Putra Indonesia 'YPTK' Padang. Al-Jabar: Jurnal Pendidikan Matematika, 8 (1), $53-62$.

Dewimarni, Syelfia. (n.d.). Pengembangan Media Pembelajaran Berbasis Android Untuk Meningkatkan Kemampuan Pemahaman Konsep Statistika. Jurnal Ilmu Pendidikan Ahlussunnah, Vol. IV, No. 1.

Hafiz, M. (2013). Research and Development: Penelitian di Bidang Pendidikan yang Inovatif, Produktif dan Bermakna. 16, $n$.

Hamzah, N. L. (2011). Teknologi Komunikasi \& Informasi Pembelajaran. PT. Bumi Aksara.

Insar Damopolii, B. K. (n.d.). The Development Of Android-Based Mobile Learning Supported By Problem-Based Learning Strategy For Students' Learning Success. International Journal of Scientific \& Technology Research., Volume 8(Issue 07).

Jusniar \& Sumiati. (2014). Pengembangan Perangkat Assesment Berbasis Keterampilan Generik Sains (KGS) pada Mata Kuliah Praktikum Kimia Fisika II. 1, no.

Muliyardi. (2006). Pengembangan Model Pembelajaran Matematika dengan Menggunakan Komik di Kelas I Sekolah Dasar. Surabaya. Pasca Sarjana UNESA.

NCTM. (1989). Curriculum Evaluation Standard for School Mathematics. The NCTM Inc.

Plomp, T. (2013). Educational Design Research. SLO-Netherland Intitute for Curriculum development.

Rudi, S. (n.d.). Rancang Bangun Media Pembelajaran Berbasis Android Tanpa Coding Semudah Menyusun Puzzle. Jurnal Sistem Informasi Dan Sains Teknologi, Vol.2, No.2.

Shinta. K.W. (2017). Pengaruh Penggunaan Peta Konsep Dalam Pembelajaran Matematika Terhadap Hasil Belajar Siswa. Skripsi. [Skripsi. Tidak dipublikasikan]. https://core.ac.uk/download/pdf/148617054.pdf.

syaful \& Arswan. (2010). Strategi Belajar Mengajar. Rineka Cipta. Edisi Revisi.

Vulandari, T. retno. (2018). Bahan Ajar mata kuliah statistika. https://eprints.sinus.ac.id/467/1/bahanajar-statistik-tid3-retno.pdf Diakses 25 Januari 2021.

Walpole, E. R. (1992). PengantarStatistika. Gramedia Pustaka Utama. 